\title{
FIXED POINTS AND THEIR APPROXIMATIONS FOR ASYMPTOTICALLY NONEXPANSIVE MAPPINGS IN LOCALLY CONVEX SPACES
}

\author{
P. VIJAYARAJU \\ Department of Mathematics \\ Anna University \\ Madras 600025 \\ India
}

(Received March 19, 1992)

\begin{abstract}
We construct an example that the class of asymptotically nonexpansive mappings include properly the class of nonexpansive mappings in locally convex spaces, prove a theorem on the existence of fixed points, and the convergence of the sequence of iterates to a fixed point for asymptotically nonexpansive mappings in locally convex spaces.
\end{abstract}

KEY WORDS AND PHRASES. Fixed points, asymptotically nonexpansive, uniformly asymptotically regular maps.

1992 AMS SUBJECT CLASSIFICATION CODES. 47H10, 46006.

\section{INTRODUCTION}

Some results concerning fixed point theorems for nonexpansive mappings on locally convex spaces have been obtained by Taylor [5], Su and Sehgal [6], Tarafdar [4] and others. Su and Sehgal [6] have extended a theorem of Taylor [5] for nonexpansive self-mapping of a compact starshaped subset $K$ of a locally convex space $X$, to nonexpansive non-self mapping $T$ of $K$ into $X$ with $T(\partial K) \subset K$, where $\partial K$ denotes the boundary of $K$. In 1972, Goebel and Kirk [2] have introduced the notion of asymptotically nonexpansive mappings in Banach spaces and they have proved fixed point theorems for such mappings in uniformly convex Banach spaces.

The author [7] has introduced in 1988 the notion of asymptotically nonexpansive mappings (see Def: 1.1 (iii)) and uniformly asymptotically regular mappings (see Def. 1.1 (iv)) in locally convex spaces $X$ and showed in [7] that if $K$ is a weakly compact star-shaped subset of $X$ and $\mathrm{T}: \mathrm{K} \rightarrow \mathrm{K}$ is asymptotically nonexpansive, uniformly asymptotically regular and $I-T$ is demiclosed, then $T$ has a fixed point in $K$, where $I$ denotes the identity map. In the second section of this paper, we prove that the 
condition $T: K \rightarrow K$ in $\left[7\right.$ ] may be weakened to $T: K \rightarrow X$ with $T^{n}(\partial K) \subset K$ for every positive integer $n$.

In the third section, we prove the convergence of the sequence of iterates to a fixed point for asymptotically regular, asymptotically nonexpansive self-mapping in a locally convex space. This result extends those of Theorem 3.3 of Taylor [5] for asymptotically regular, nonexpansive self-mappings.

Here and later, let $x$ denote a locally convex Hausdorff linear topological space with a family $\left(p_{\alpha}\right)_{\alpha \in J}$ of seminorms which defines the topology on $X$, where $J$ is any index set.

We recall the following definition.

DEFINITION 1.1. Let $K$ be a nonempty subset of $X$. If $T$ maps $K$ into $X$, we say that

i) $T$ is contractive (i.e., $p_{\alpha}$-contractive) [6] if

$$
\begin{aligned}
& \mathrm{p}_{\alpha}(\mathrm{TX}-\mathrm{TY})<\mathrm{p}_{\alpha}(\mathrm{x}-\mathrm{y}) \text { if } \mathrm{p}_{\alpha}(\mathrm{x}-\mathrm{y}) \neq 0 \\
&=0 \text { if } \mathrm{p}_{\alpha}(\mathrm{x}-\mathrm{y})=0 \\
& \text { for each } \mathrm{x}, \mathrm{y} \in \mathrm{K} \text { and for each } \alpha \epsilon \mathrm{J} ;
\end{aligned}
$$

ii) $T$ is nonexpansive (i.e., $p_{\alpha}$-nonexpansive) [6] if

$$
\mathrm{p}_{\alpha}(\mathrm{Tx}-\mathrm{Ty}) \leq \mathrm{p}_{\alpha}(\mathrm{x}-\mathrm{y}) \text { for each } \mathrm{x}, \mathrm{y} \in \mathrm{K} \text { and for each } \alpha \epsilon \mathrm{J} \text {; }
$$

iii) $T$ is asymptotically nonexpansive [7] if

$$
p_{\alpha}\left(T^{n} x-T^{n} y\right) \leq k_{n} p_{\alpha}(x-y)
$$

for each $x, y \in K$, for each $n$ and for each $\alpha \in J$, where $\left\{k_{n}\right\}$ is a sequence of real numbers such that $k_{n} \rightarrow 1$ as $n \rightarrow \infty$.

It is assumed that $k_{n} \geq 1$ and $k_{n} \geq k_{n+1}$ for $n=1,2, \ldots$;

iv) $T$ is uniformly asymptotically regular [7] if for each $\alpha$ in $J$ and $\eta>0$, there exists a $N(\alpha, \eta)$ such that

$$
p_{\alpha}\left(T^{n} x-T^{n+1} x\right)<\eta
$$

for all $\mathrm{n} \geq \mathrm{N}(\alpha, \eta)$ and for all $\times \epsilon \mathrm{K}$; and

v) $T$ is asymptotically regular on $K$ [4] if, for each $x \in K$ and $\alpha \in J$,

$$
\lim _{n \rightarrow \infty} p_{\alpha}\left(T^{n} x-T^{n+1} x\right)=0 .
$$

DEFINITION 1.2. A mapping $T$ from $K$ to $X$ is said to be demiclosed [5] if, for every net $\left(x_{\beta}\right)$ in $k$ such that $\left(x_{\beta}\right)$ weakly converges to $x$ in $K$ (i.e., $x_{\beta} \rightarrow X$ ) and $\left(T x_{\beta}\right)$ converges to $y$ in $X\left(i . e ., T x_{\beta} \rightarrow y\right.$ ) we have $\mathrm{TX}=\mathrm{y}$.

The following example shows that the class of asymptotically nonexpansive mappings is wider than the class of nonexpansive mappings in locally convex spaces.

EXAMPLE 1.1. Let $X=$ space( $s$ ), the space of all sequences of complex numbers whose topology is defined by the family of seminorms $p_{n}$ defined by 


$$
p_{n}(x)=\max _{1 \leq i \leq n}\left|\xi_{i}\right| \text { for } x=\left(\xi_{1}, \xi_{2}, \ldots\right) \in x \text { and } n=1,2, \ldots
$$

Let $\mathrm{K}=\left\{\mathrm{x}=\left(\xi_{1}, \xi_{2}, \ldots\right) \in \mathrm{x}:\left|\xi_{1}\right| \leq 1 / 2\right.$ and $\left|\xi_{j}\right| \leq 1$ for $\left.j=2, \ldots\right\}$. Define a map $\mathrm{T}$ from $\mathrm{K}$ to $\mathrm{K}$ by

$$
\mathrm{Tx}=\left(0,2 \xi_{1}, A_{2} \xi_{2}, \ldots, A_{k} \xi_{k}, \ldots\right)
$$

for all $x=\left(\xi_{1}, \xi_{2}, \ldots, \xi_{k}, \ldots\right) \in K$, where $\left\{A_{i}\right\}$ is a sequence of real numbers in $(0,1)$ such that $\prod_{i=2}^{\infty} A_{i}=1 / 2$.

Let $a=(1 / 2,0, \ldots), b=(0, \ldots) \in K$. Then we have

$$
\mathrm{p}_{2}(\mathrm{Ta}-\mathrm{Tb})=1>1 / 2=\mathrm{p}_{2}(\mathrm{a}-\mathrm{b})
$$

and hence $\mathrm{T}$ is not nonexpansive.

Now, let $x=\left(\xi_{1}, \xi_{2}, \ldots, \xi_{k}, \ldots.\right), y=\left(\eta_{1}, \eta_{2}, \ldots, \eta_{k}, \ldots\right) \quad \mathrm{K}$.

Then $\quad p_{n}(T x-T y) \leq 2 p_{n}(x-y)$ for $n=1,2, \ldots$ and

$$
\mathrm{T}^{\mathrm{m}}(\mathrm{x})=\left(0, \ldots, 0,2 \prod_{i=2}^{\mathrm{m}} \mathrm{A}_{i} \xi_{1}, \prod_{i=2}^{\mathrm{m}+1} \mathrm{~A}_{i} \xi_{2}, \ldots, \prod_{i=k}^{m+k-1} A_{i} \xi_{k}, \ldots\right) \text {. }
$$

Therefore $p_{n}\left(T^{m}(x)-T^{m}(y)\right)=0$ for $m \geq n$.

If $m<n$, then $m=n-k$, where $k>0$ and $n>k$

and therefore $p_{n}\left(T^{m}(x)-T^{m}(y)\right)$

$=\max \left[\left[2 \prod_{i=2}^{m} A_{i}\right]\left|\xi_{1}-\eta_{1}\right|, \quad\left[\prod_{i=2}^{m+1} A_{i}\right]\left|\xi_{2}-\eta_{2}\right|, \ldots, \quad\left[\prod_{i=k}^{m+k} A_{i}^{-1}\right]\left|\xi_{k}-\eta_{k}\right|\right]$

$\leq \max \left[2 \prod_{i=2}^{m} A_{i}, \quad \prod_{i=2}^{m+1} A_{i}, \quad \prod_{i=3}^{m+2} A_{i}, \ldots, \prod_{i=k}^{m+k} A_{i}\right] p_{k}(x-y)$

$\leq 2 \prod_{i=2}^{m} A_{i} p_{n}(x-y)=k_{m} p_{n}(x-y)$,

where $k_{m}=2 \prod_{i=2}^{m} A_{i} \rightarrow 1$ as $m \rightarrow \infty$.

Hence $\mathrm{T}$ is asymptotically nonexpansive. Also $\mathrm{T}$ is uniformly asymptotically regular on $\mathrm{K}$.

The following example due to the author in [7] shows that the uniform asymptotic regularity is stronger than asymptotic regularity.

EXAMPLE 1.2. Let $x=\rho p, 1<p<\infty$. Let $k$ denote the unit ball in $x$. Define a map $\mathrm{T}: \mathrm{K} \rightarrow \mathrm{K}$ by

$$
\mathrm{Tx}=\left(\xi_{2}, \xi_{3}, \ldots\right) \text { for all } \mathrm{x}=\left(\xi_{1}, \xi_{2}, \ldots\right) \epsilon \mathrm{K} \text {. }
$$

Then $\mathrm{T}$ is asymptotically regular but not uniformly asymptotically regular on $\mathrm{K}$. Also $\mathrm{T}$ is nonexpansive and hence $\mathrm{T}$ is asymptotically nonexpansive. DEFINITION 1.3. A nonempty subset $K$ of $X$ is said to be star-shaped [1] provided that there is at least one element $x$ in $K$ such that if $y$ is any element of $K$ and $t \epsilon(0,1)$, then $(1-t) x+t y \epsilon K$. Such a point $x$ is 
called a star-center of $K$. Every convex set is a star-shaped set but the converse is not true.

\section{MAIN RESULTS}

2. FIXED POINTS OF ASYMPTOTICALLY NONEXPANSIVE MAPPINGS

For the proof of Theorem 2.1, we need the following lemma due to su and Sehgal [6, Theorem 2].

LEMMA 2.1. Let $K$ be a nonempty compact subset of $x$. Let $T$ be $a$ contractive mapping of $K$ into $x$ such that $T(\partial K) \subset K$. Then $T$ has a unique fixed point in $K$.

Taylor [5] has proved a result on the existence of fixed points for nonexpansive self-mapping $T$ of a nonempty compact star-shaped subset $K$ of a locally convex space $x$. This result was extended by su and sehgal [6] to nonexpansive non-self mapping $T$ of $K$ into $X$ by assuming the condition that $T(\partial K) \subset K$. We extend the corresponding theorem for asymptotically nonexpansive, uniformly asymptotically regular mappings. The following theorem is new even in the case of Banach spaces.

THEOREM 2.1. Let $T$ be a mapping of $X$ into itself. Let $K$ be $a$ nonempty compact star-shaped subset of $x$. Let $T$ be an asymptotically nonexpansive, uniformly asymptotically regular mapping of $K$ into $x$ such that $T^{n}(\partial K) \subset K$ for every $n=1,2, \ldots$ Then $T$ has a fixed point in $K$.

PROOF. Let $Y$ be a star center of $K$. Define a map $T_{n}$ from $K$ to $X$ by $\mathrm{T}_{\mathrm{n}} \mathrm{x}=\mathrm{a}_{n} \mathrm{~T}^{\mathrm{n}} \mathrm{x}+\left(1-\mathrm{a}_{\mathrm{n}}\right)$ y for all $\mathrm{x} \in \mathrm{K}, \mathrm{n}=1,2, \ldots$,

where $a_{n}=(1-(1 / n)) / k_{n}$ and $\left\{k_{n}\right\}$ is as in Definition 1.1 (iii). Then each $T_{n}$ clearly maps $K$ into $x$.

If $x, z \in K$, then since $T$ is asymptotically nonexpansive, we have

$$
p_{\alpha}\left(T_{n} x-T_{n} z\right)=a_{n} p_{\alpha}\left(T^{n} x-T^{n} z\right) \leq(1-(1 / n)) p_{\alpha}(x-z) .
$$

Therefore $T_{n}$ is a contraction of $K$ into $x$ and hence a contractive mapping of $K$ into $x$.

Since $T^{n}(\partial K) \subset K$ and $K$ is star-shaped, $T_{n}(\partial K) \subset K$.

Therefore by Lemma $2.1, T_{n}$ has a unique fixed point, say, $x_{n}$ in $k$.

Therefore, $x_{n}-T^{n} x_{n}=\left(1-a_{n}\right)\left(y-T^{n} x_{n}\right) \rightarrow 0$ as $n \rightarrow \infty$, since $k$ is bounded and $a_{n} \rightarrow 1$ as $n \rightarrow \infty$.

since $T$ is uniformly asymptotically regular, it follows that

$$
\mathrm{T}^{\mathrm{n}} \mathrm{x}_{\mathrm{n}}-\mathrm{T}^{\mathrm{n}+1} \mathrm{x}_{\mathrm{n}} \rightarrow 0 \text { as } \mathrm{n} \rightarrow \infty \text {. }
$$

From (2.1) and (2.2) we obtain

$$
\mathrm{T}^{\mathrm{n}+1} \mathrm{x}_{\mathrm{n}}-\mathrm{x}_{\mathrm{n}} \rightarrow 0 \text { as } \mathrm{n} \rightarrow \infty \text {. }
$$

Now

$$
\begin{aligned}
p_{\alpha}\left(T x_{n}-x_{n}\right) & \leq p_{\alpha}\left(T x_{n}-T^{n+1} x_{n}\right)+p_{\alpha}\left(T^{n+1} x_{n}-x_{n}\right) \\
& \leq k_{1} p_{\alpha}\left(x_{n}-T^{n} x_{n}\right)+p_{\alpha}\left(T^{n+1} x_{n}-x_{n}\right)
\end{aligned}
$$


Using (2.1) and (2.3) in (2.4) we get

$$
\mathrm{T} \mathrm{x}_{\mathrm{n}}-\mathrm{x}_{\mathrm{n}} \rightarrow 0 \text { as } \mathrm{n} \rightarrow \infty \text {. }
$$

Since $k$ is compact and $\left\{x_{n}\right\} \subset k$, there is a subnet $\left(x_{\beta}\right)$ of the sequence $\left\{x_{n}\right\}$ such that $x_{\beta} \stackrel{\beta}{\rightarrow} x \in K$.

Therefore $(I-T)\left(X_{\beta}\right) \stackrel{\beta}{\rightarrow}(I-T) x$ and by $(2.5),(I-T)\left(x_{\beta}\right) \stackrel{\beta}{\rightarrow} 0$. Since $x$ is Hausdorf $f$, it follows that $(I-T) x=0$. Thus $x$ is a fixed point of $T$ in $K$.

\section{CONVERGENCE OF ITERATES OF ASYMPTOTICALLY NONEXPANSIVE MAPPING}

Taylor [5] has proved that the sequence of iterates converges to a fixed point for nonexpansive self-mapping in a locally convex space. This result is extended below to asymptotically nonexpansive self-mapping.

We use the following definition to prove our Theorem 3.2.

DEFINITION 3.1. A point $x$ in a topological space $x$ is called a cluster point [3] of $a$ net $S$ if and only if $S$ is frequently in every neighbourhood of $x$.

THEOREM 3.2. Let $K$ be a nonempty closed bounded subset of $X$. Let $T$ be a continuous, asymptotically regular self-mapping of $K$. Assume that $I$ - $T$ maps closed subsets of $K$ into closed subsets of $X$, where $I$ denotes the identity mapping. Then, for each $x \in K$, the sequence of iterates $\left\{T^{n} \mathrm{X}\right\}$ clusters at a fixed point of $T$ and each such cluster point is fixed by $T$. If, in addition, $T$ is an asymptotically nonexpansive self-mapping of $K$, then every sequence $\left\{T^{n}\right.$ \} converges to a fixed point of $T$.

PROOF. Let $T$ be a continuous, asymptotically regular self-mapping of $K$. Let $x \in K$ and $M$ denote the closure of $\left\{T^{n} x\right\}$. Since $T$ is asymptotically regular, it follows that

$$
\mathrm{T}^{\mathrm{n}} \mathrm{X}-\mathrm{T}^{\mathrm{n}+1} \mathrm{X} \rightarrow 0 \text { as } \mathrm{n} \rightarrow \infty .
$$

Therefore 0 lies in the closure of $(I-T)(M)$. Since $M$ is closed and $I$ - $T$ maps closed subsets of $K$ into closed subsets of $X$, it follows that $(I-T)(M)$ is closed. Therefore $0 \in(I-T)(M)$ and hence there is a point $y$ in $M$ such that $(I-T)(Y)=0$.

since $y \in M$, either $y \in\left\{T^{n} x\right\}$ or $y$ is a cluster point of $\left\{T^{n} x\right\}$. If $y=T^{m} x$ for some $m$, then

$$
T^{n+m}(x)=T^{n}\left(T^{m} x\right)=T^{n} y=y \quad \text { for } n=1,2, \ldots
$$

Therefore $T^{k} x=y$ if $k>m$. Hence $y$ is a cluster point of $\left\{T^{n} x\right\}$. Let $z$ be any cluster point of $\left\{T^{n} \times\right.$.

We know that a point $b$ in a topological space $x$ is a cluster point of $a$ net $S$ if and only if some subnet of $s$ converges to $b$ [3].

Therefore there is a subnet $\left(T^{\beta} x\right)$ of $\left\{T^{n} x\right\}$ such that $T^{\beta} X \stackrel{\beta}{\rightarrow} z$. 


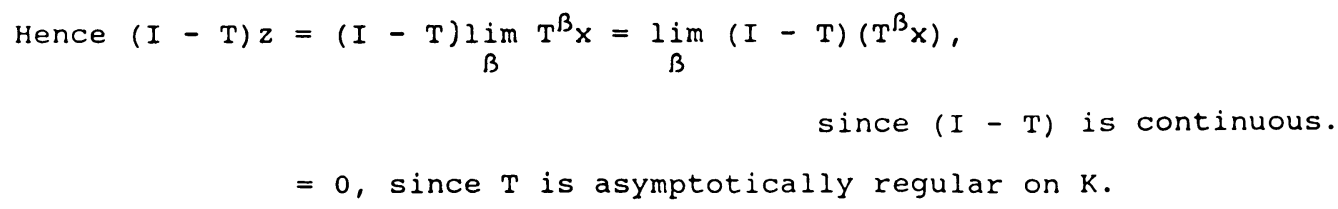

Thus $z$ is a fixed point of $T$.

Assume further that $\mathrm{T}$ is an asymptotically nonexpansive self-mapping of K. We already know that $y$ is a cluster point of $\left\{T^{n} x\right\}$.

Therefore for each $\alpha \epsilon J$ and $\delta>0$, there exists an integer $m$ such that

$$
\mathrm{p}_{\alpha}\left(\mathrm{T}^{\mathrm{m}} \mathrm{x}-\mathrm{y}\right)<\delta \text {. }
$$

Since $\mathrm{T}$ is asymptotically nonexpansive, it follows that

$$
p_{\alpha}\left(T^{n-m}\left(T^{m_{x}}\right)-T^{n-m_{y}}\right) \leq k_{n-m} p_{\alpha}\left(T^{m_{x}}-y\right) \text { for } n \geq m \text {. }
$$

From (3.1) we obtain

$$
p_{\alpha}\left(T^{n} x-y\right)<k_{n-m} \delta .
$$

Therefore

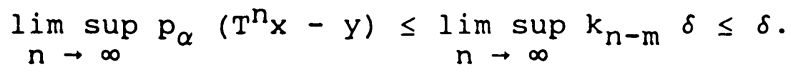

Hence

$$
\lim _{n \rightarrow \infty} p_{\alpha}\left(T^{n} x-y\right)=0
$$

That is, the sequence $\left\{\mathrm{T}^{\mathrm{n}} \mathrm{X}\right\}$ converges to a fixed point of $\mathrm{T}$.

ACKNOWLEDGEMENT. The author would like to thank Prof.T.R. Dhanapalan for his guidance and encouragement in the preparation of this paper. The author wishes to thank the referees for suggestions that lead to a better presentation of this paper.

\section{REFERENCES}

1. DOTSON, W.G. (JR). Fixed point theorems for nonexpansive mappings on star-shaped subsets of Banach spaces, I. London Math. Soc. 4 (1972), 408-410.

2. GOEBEL, K. and W.A.KIRK. A fixed point theorem for asymptotically nonexpansive mappings, Proc. Amer. Math. Soc. 35 (1972), 171-174.

3. KELLEY, J.L. General Topology, Van Nostrand, Princeton, NJ, 1955.

4. TARAFDAR, E. An approach to fixed point theorems on uniform spaces, Trans. Amer. Math. Soc. 191 (1974), $209-225$.

5. TAYLOR, W.W. Fixed point theorems for nonexpansive mappings in linear topological spaces, J. Math. Anal. Appl. 40 (1972), 164-173.

6. SU.C.H. and V.M.SEHGAL. Some fixed point theorems for nonexpansive mappings in locally convex spaces, Boll. Un. Mat. Ital. 10 (1974), 598-601.

7. VIJAYARAJU, P. Fixed point theorems for asymptotically nonexpansive mappings, Bul1. Calcutta Math. Soc. 80 (1988), 133-136. 


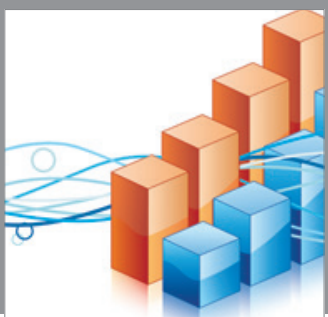

Advances in

Operations Research

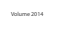

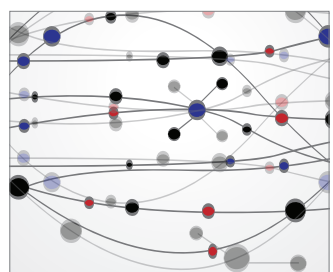

\section{The Scientific} World Journal
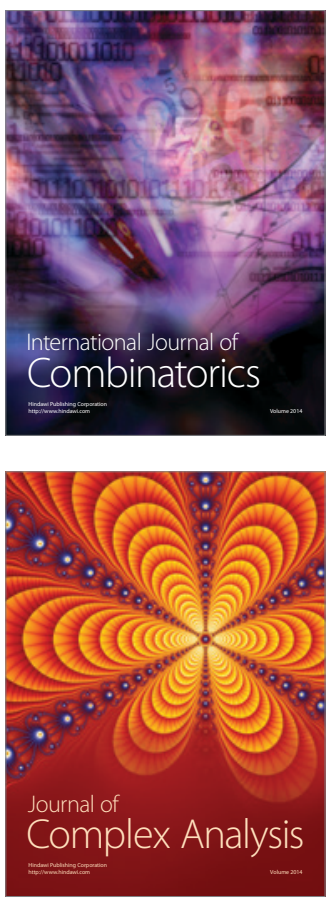

International Journal of

Mathematics and

Mathematical

Sciences
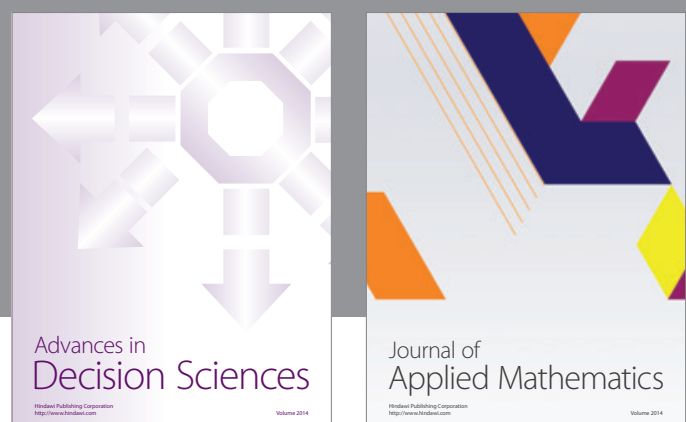

Journal of

Applied Mathematics
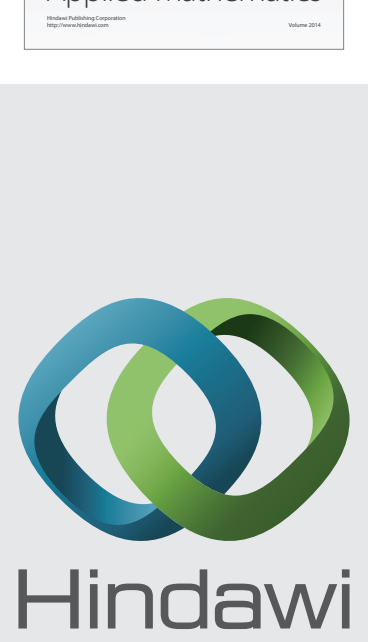

Submit your manuscripts at http://www.hindawi.com
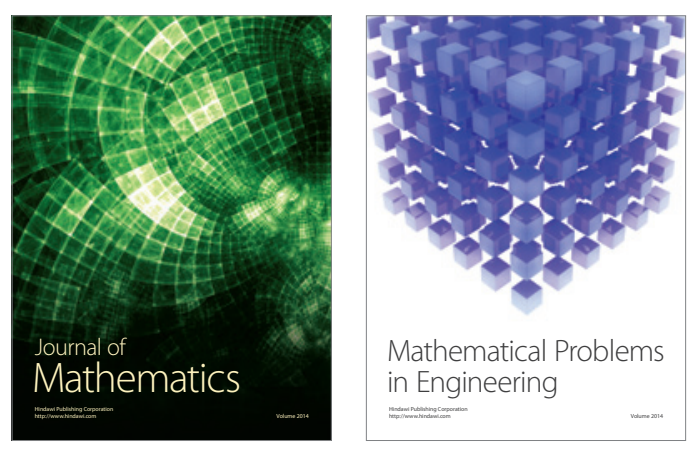

Mathematical Problems in Engineering
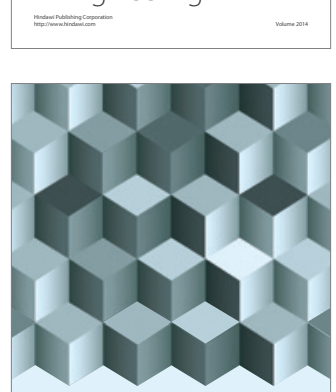

Journal of

Function Spaces
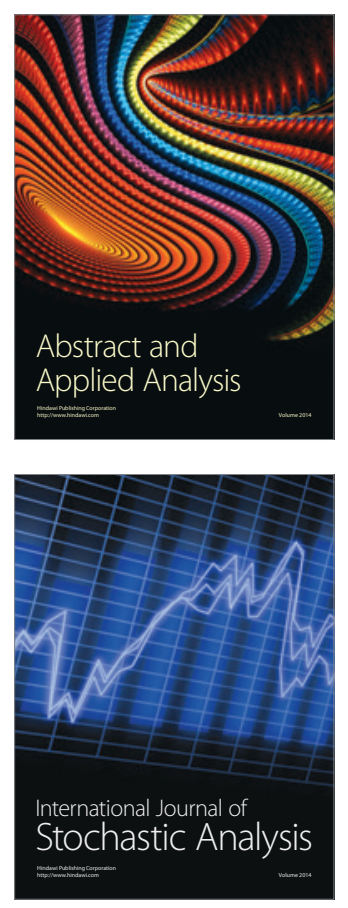

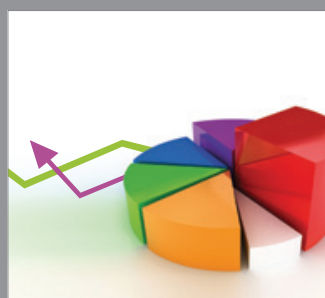

ournal of

Probability and Statistics

Promensencen
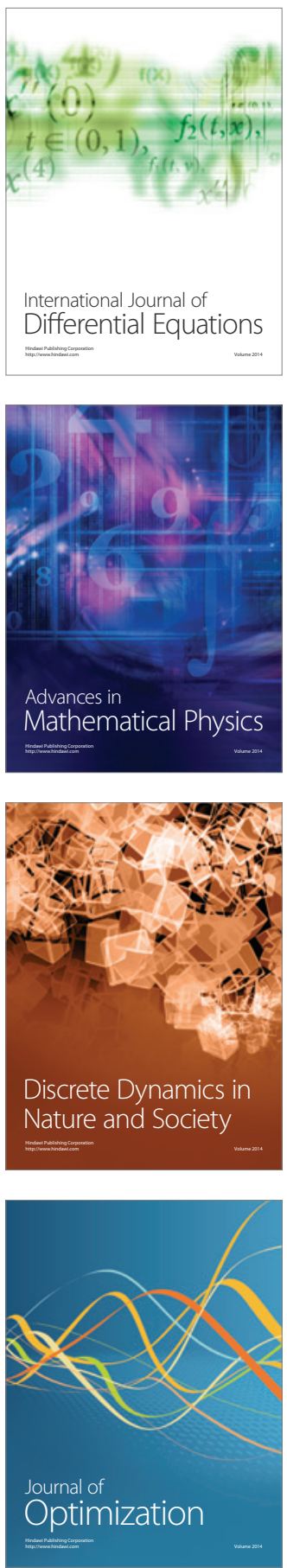